\title{
OBACIS Phase II: Catalogs and Auto-Generated Course Information Sheets
}

\author{
Mohamed A. Ismail \\ Industrial Systems Engineering, University of Regina \\ mohamed.ismail@uregina.ca
}

\begin{abstract}
OBACIS is an integrated framework being developed to accelerate the accreditation reporting workflow, cut down the reporting cost by an order of magnitude, and close the data-driven continuous improvement loop. The framework integrates three different pieces of software: 1) an Excel Add-in, or the "XlApp”, for simultaneous grade and OBA reporting; 2) $A$ Windows Application, or the "Win-App" for program and faculty-level template creation, document compilation, and program assessment; and, 3) a web-tool, or the "WebApp", for document compilation and reporting. This paper focuses on creating a centralized database for compiling raw data related to accreditation reporting from various resources such as previous visit accreditation reports, academic calendars, course schedules, and a handful of other resources are used to create what we call OBACIS Catalogs. The Catalogs framework is a part of the bigger OBACIS framework proposed in CEEA 2016 [1]. The framework has been implemented as a module of the WinApp. Automating the creation process of Course Information Sheets (CIS) was the original goal and is still one of the main outputs of the proposed framework. The OBACIS Catalogs are supposed to save a sheer amount of time needed for accreditation reporting and should act as an instrumental tool for accelerating accreditation data collection, creating insightful analyses, and identifying gaps for continuous improvement initiatives at both program and faculty levels.
\end{abstract}

Keywords: Accreditation Software, Outcome-Based Assessment, Continuous Improvement, Engineering Education

\section{INTRODUCTION}

The new outcome-based assessment process is timeconsuming and data-intensive. Switching from the previous event-based process that happens every three or six years to a continuously improving one makes the process more overwhelming and costly than it simply looks
[1]. There is no such a comprehensive off-the-shelf solution that is readily available to facilitate, organize or guide the process of data collection. Many institutions have been developing their systems to collect, manage and distribute this data [2]. Unfortunately, there is little information on how institutions are developing their respective systems, and even less information on their specific aspects, viewpoints, goals or barriers [3]. Accreditation activities are becoming overwhelming, and software tools are much needed to assist in data collection, data analytics and closing the continuous improvement loop. The current tools are still premature, and there is a dearth of integrated frameworks that address the new accreditation and its continuous improvement cycle.

Of all the software tools currently in use, Excel is the most commonly used one for graduate attributes data collection and course activities assessment. Excel reporting capabilities can be extended using office automation, i.e. Excel Add-Ins. Brennan et al. [4] have used Excel forms for linking course learning outcomes to course assessments activities. Student achievement reports have been generated and utilized for continual improvement activities. During OBACIS' first phase of development, we introduced a tri-mapping and reporting system using an Excel Add-in, the Xl-App, for graduate attributes, learning outcomes, and categorical analytics [1]. The add-in was driven from the Win-App environment. Currently, the XlApp is a full-fledged one that could be distributed to faculty members to be used for grade reporting automation and collecting all accreditation relevant data [5].

Collecting data for individual stakeholders need a program or a faculty level tool. Web tools are the most appropriate to achieve the task of distributed data collection. The ABET's course assessment tool (ACAT) system [6] of the University of Nevada, and the CEAB's Accreditation Management System (AMS) of University of Alberta [7] are typical examples. Another example of using Web tools for course learning outcomes mapping and analytics is reported in [8]. 
Tools dedicated to data analytics are still missing especially at the program level. The EGAD project [9] team at Queens University have recently integrated R-studio, community software and some other open source elements to create a system for collecting, analyzing, reporting and visualizing graduate attributes [2]. The framework's rich graphics and comparative results is a good step in the right direction of analyzing the data collected and closing the continuous improvement loop.

OBACIS is an integrated framework that we are currently developing to support most of the accreditation activities throughout its life cycle. OBACIS integrates Office, Windows, and Web technologies to streamline and help different stakeholders manage the entire process and maximize its benefits. OBACIS is shorthand for OutcomeBased Assessment and Continuous Improvement System. The basic objective is to automate the data-collection process, cut down its time and cost by an order of magnitude, and switch the paradigm from that dominated by data collection to the one dominated by data-informed improvement initiatives and action plans. The framework's first draft has been presented in [1]. Figure 1 demonstrates the latest update of the system framework. This paper presents the second phase of development: the catalogs and the automation process of creating course information sheets. The project started in early 2016 while reviewing the latest questionnaire published by $\mathrm{CEAB}$ that states clearly the new requirement of the accreditation process [10]. The accreditation reporting package has been augmented by a set of macro-enabled Excel sheets that help in creating most of the data tables required for accreditation reporting. The new package presents a new structure for the course information sheets (CIS). The new sheets have several parts that cover basic course information, graduate attributes, Accreditation Units (AU) calculations and the new K-factor, course logistics (instructors' info, learning outcomes, textbooks, course statistics, and lab information). The CIS is a data-rich artifact that needs quite some time to be filled in, compiled, and reported. The project started as an initiative to take advantage of this major reporting artifact by updating it on a regular basis and hooking it into the program level continuous improvement loop. Curriculum updating, monitoring $\mathrm{AU}$ progress, tracking students' success rates, and checking course delivery consistency are some examples of success performance indicators that need to be monitored at the program level. The project's challenge was how to automate the process and streamline the data collection operations. A new framework has been designed around that concept and a goal was set: the data collection process should be easy and should almost take no time. The answer was the catalogs framework and its intuitive parsing engine, see Figure 2.

\section{THE CATALOGS FRAMEWORK}

By analyzing the new CIS structure, we found that we can save a significant amount of time and effort if we can

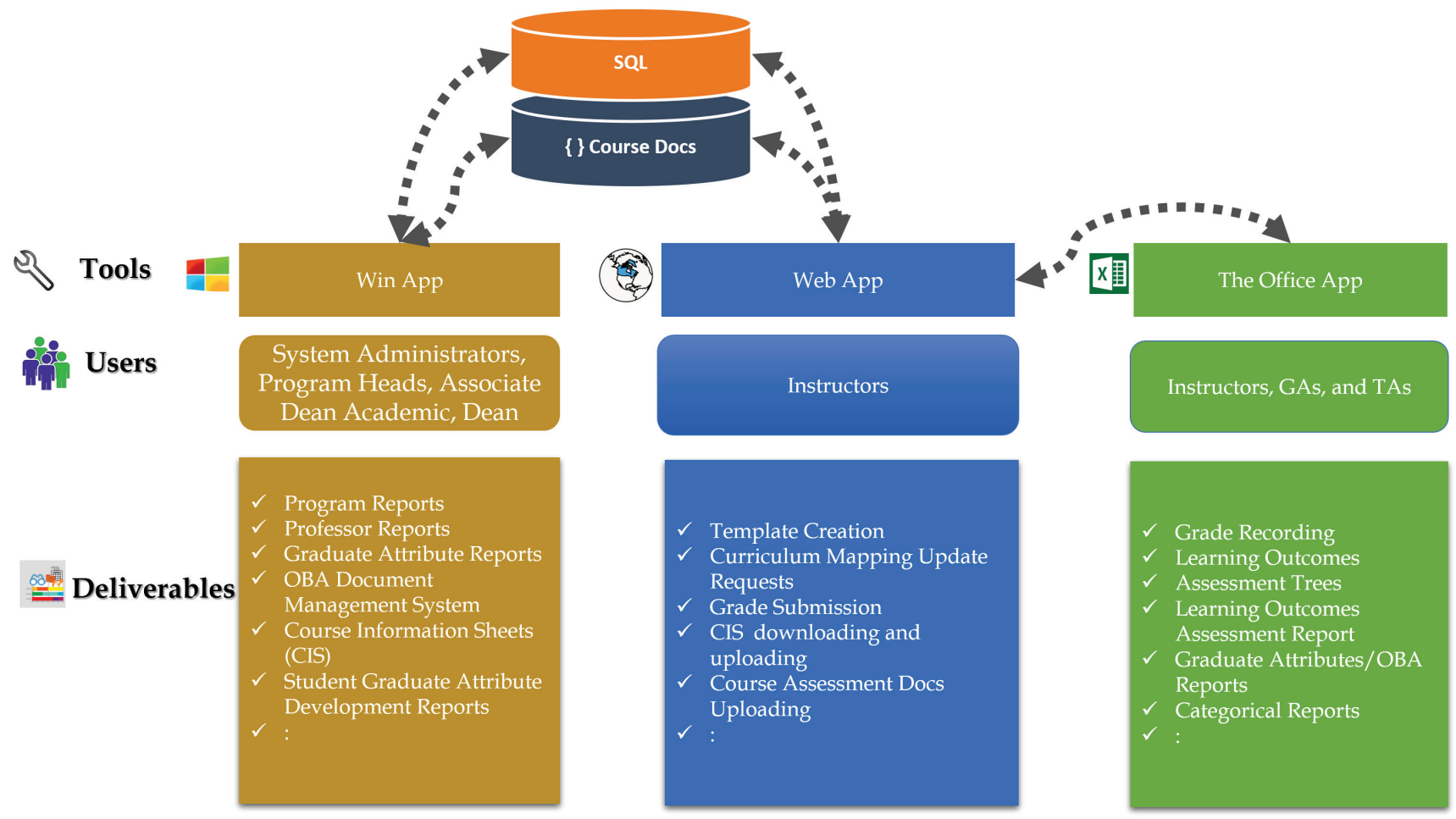

Figure 1: OBACIS framework Architecture (Last updated May 2016)

CEEA17; Paper 171

University of Toronto; June 4- 7, 2017 
work on the top of the University existing information systems and faculty documentation data. Most of CISs content can be compiled from academic calendars, curriculum maps, course syllabi, personal directories, web marking systems, and any other possible resources that could reduce significantly the time needed for data collection. The problem is that we need just some fragments of these data islands for our accreditation reporting and continuous improvement initiatives. By compiling those fragments, data-rich templates could be handed out to the teaching faculty to audit the current data

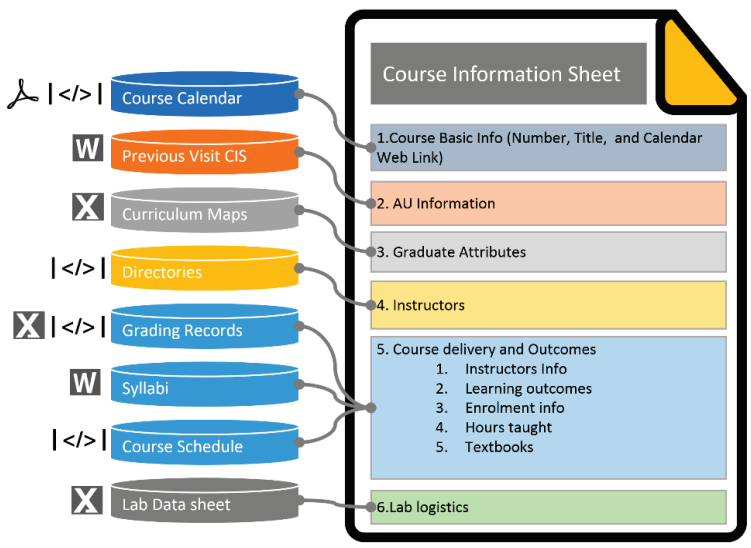

Figure 2: Catalogs Data Sources mapped to CIS basic structure

collected and have a chance to update what is needed only when needed.

The data fragments do not exist in one database. What is worse is they are not in one consistent format. The solution was to create a parsing engine that can read those fragments in their raw formats. Taking the University of Regina, $\mathrm{U}$ of $\mathrm{R}$, as an example, those data are persisted in several formats: e.g. word, excel, pdf, and HTML files. The engine turns the data collected to their corresponding data objects and persists them as XML files. OBACIS catalogs are the visual representation of those XML files and their corresponding in-memory objects, see Figures 3-11.

\section{OBACIS CATALOGS}

\subsection{Calendars}

The Calendar catalog reports all the course entries for all engineering programs curricula. The underlying database is compiled from the engineering section of the university calendar. Courses could be retrieved as individuals or as a list of courses. Using a program curriculum, a complete list of individual courses could be loaded and viewed, see Figure 3. OBACIS is designed to record a complete data set of academic calendars on a regular basis. Curriculum evolution reports could be generated to reflect curriculum development within an accreditation review cycle or an internal continuous improvement review cycle. For the latter, we recommend a two or three-year cycle.

\subsection{Graduate Attributes}

The catalogs of graduate attributes, their descriptions, and their corresponding indicators are at the core of the new OBA process. Some graduate attributes and some indicators are usually measured more often than others. Graduate Attributes achievement levels, ways of measuring indicators, how indicators could be added or removed are some tasks that add to the tall order of continuous improvement activities. Since graduate attributes are instrumental in data collection, we developed a set of icons to make referencing them easier, See Figure 4. The check boxes show indicators currently in use.

\subsection{Program Curriculum Maps}

Graduate attributes mapping to individual engineering courses is an essential part of the new accreditation reporting process. Every program is supposed to have one

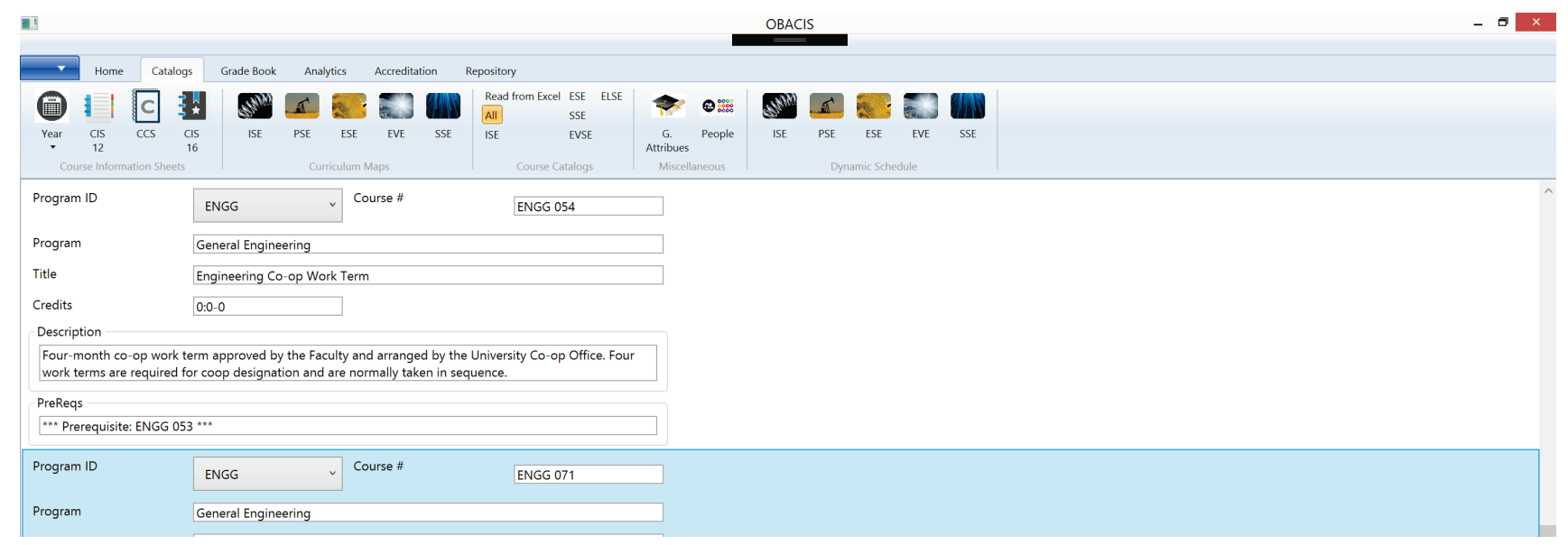

Figure 3: List view of the Engineering Academic Calendar 


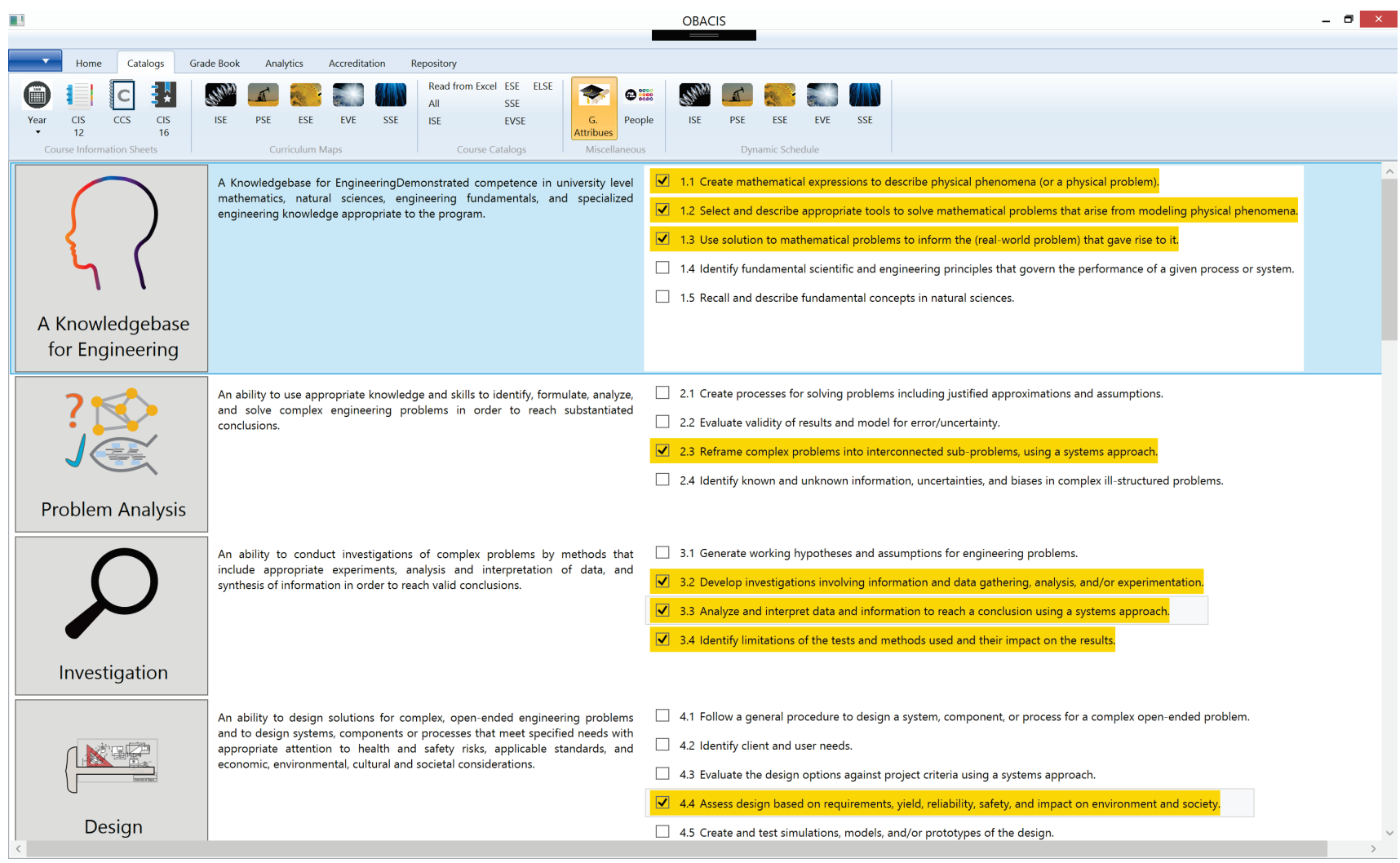

Figure 4: Graduate Attributes

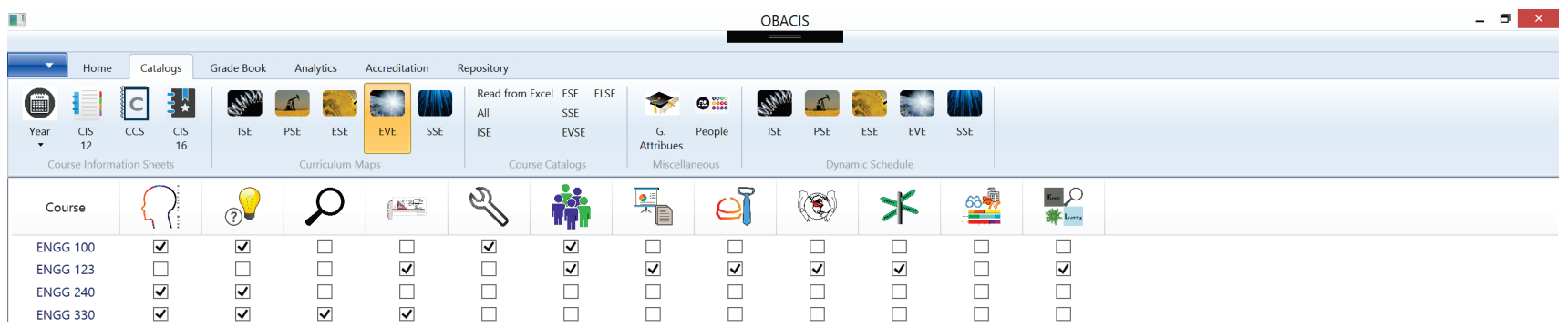

Figure 5: Program Curriculum Map (Partial View)

map. Figure 5 shows a partial map view of one of $U$ or $R$ engineering programs: We suggest the graduate mapping be reviewed on a regular basis; the process of adding/removing graduate attributes should be formalized and approved through the Outcome-Based Assessment Committee or equivalent.

\subsection{Faculty and Staff Data:}

In addition to general information about faculty and staff, CEAB collects some additional data specific to engineering faculty such as hire date, licensure status, and other relevant data mandated by CEAB. For the general information part, we have collected them from faculty and staff directory; for the CEAB specific data, a list-enabled Excel is being developed to collect the rest of data required all at once. Having this data at hand makes the instructors' info part in the new CIS done automatically as will be described later, see Figure. Sessionals and temporary teaching faculty should be added to the list as well for later use in the automatic creation of CIS.

\subsection{Academic Schedule}

The university academic schedule is the right place to get the information needed for Accreditation Units (AU) calculations and CIS logistics sections. Course logistics, credits, hours/lecture, hours/lab or hours/tutorial, calendar web links, and many other valuable pieces of data could be collected from the academic schedule directly. OBACIS keeps a year-to-year record to monitor and improve all those logistical activities. OBACIS view all schedule 


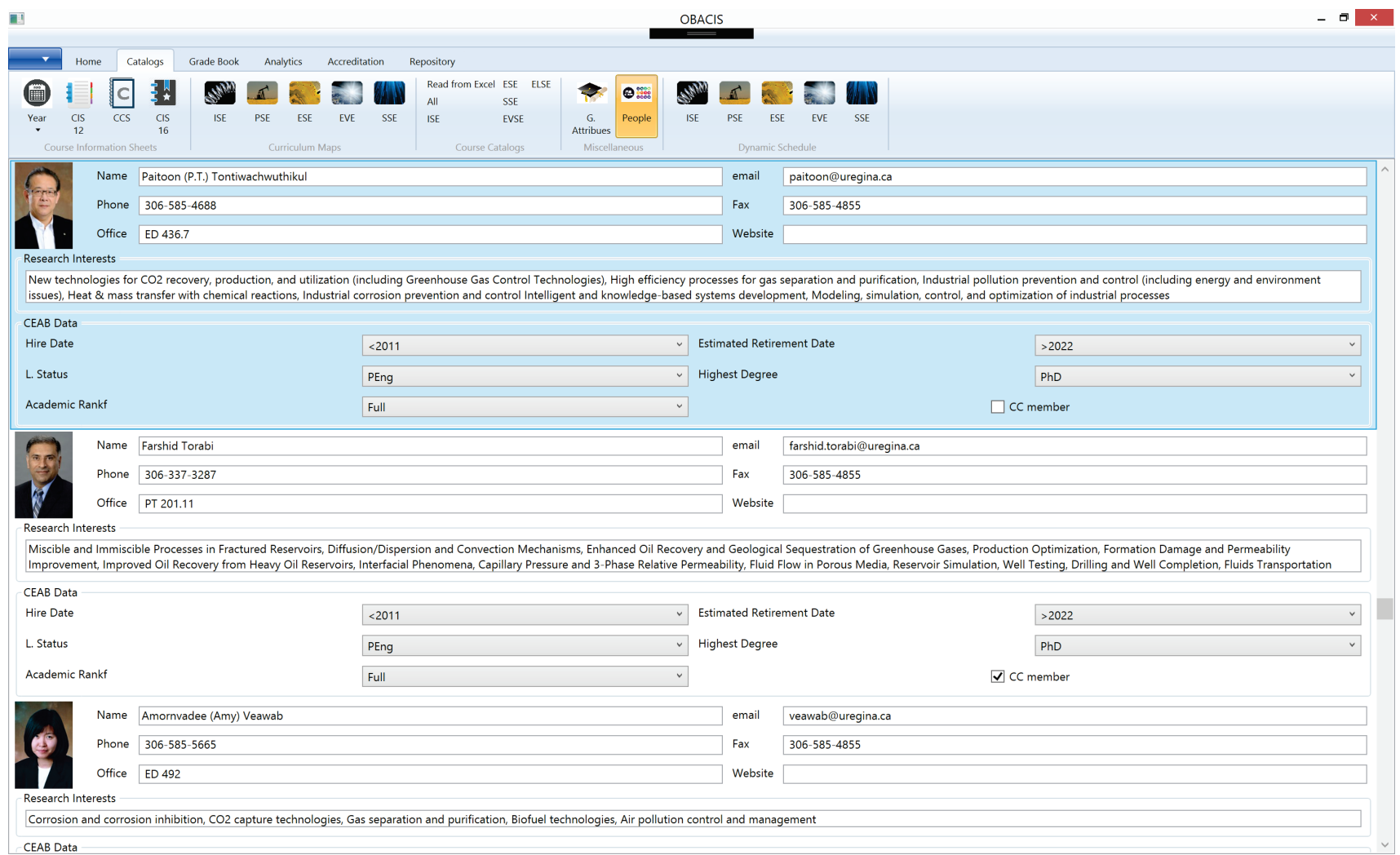

Figure 6: Faculty and Staff List

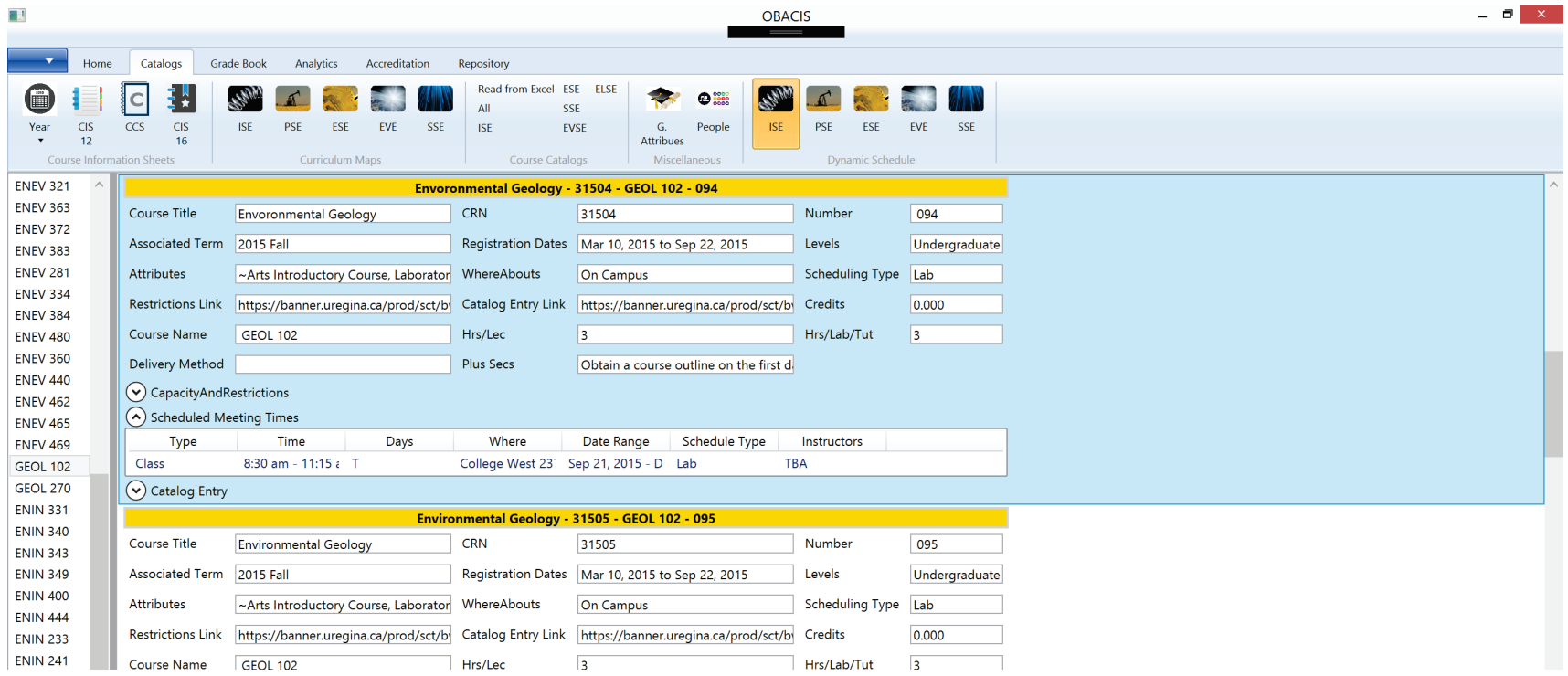

Figure 7: Couse Schedule Explorer

entries in an explorer style list. Once a course is selected, all schedule entries are listed. All lecture, lab and tutorial sections could be viewed at any time.

\subsection{Accreditation Catalogs}

CEEA17; Paper 171

University of Toronto; June 4- 7, 2017 


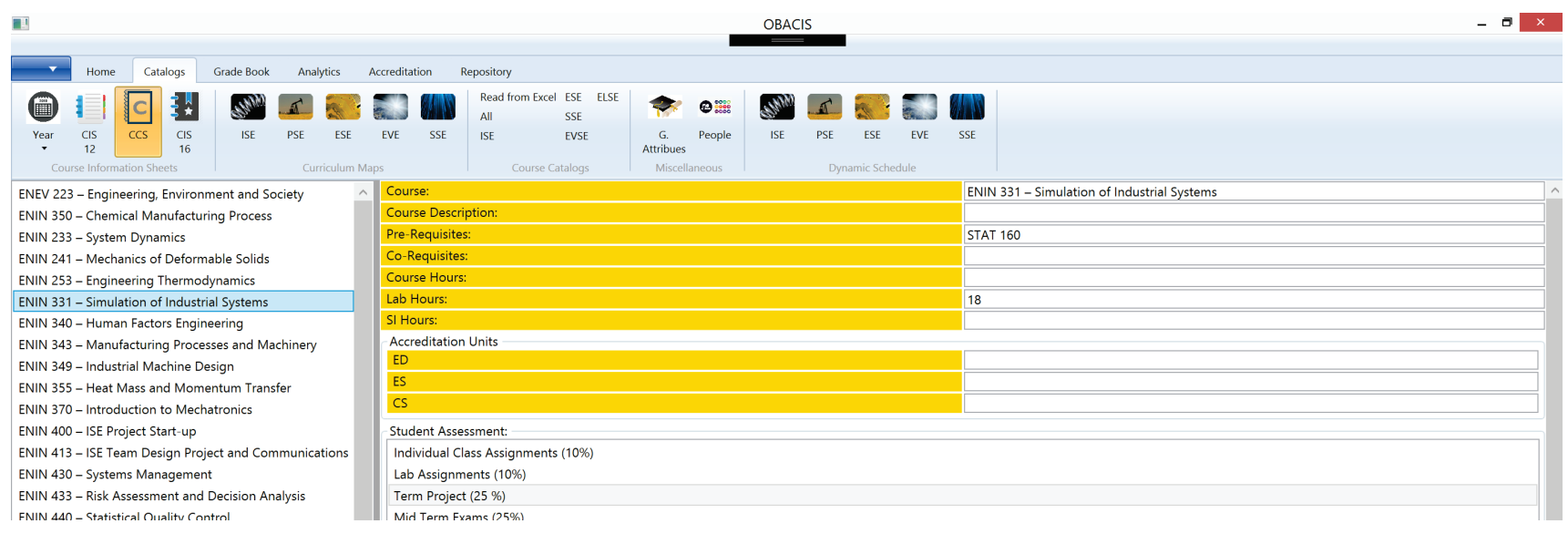

Figure 8: Course Content Sheets

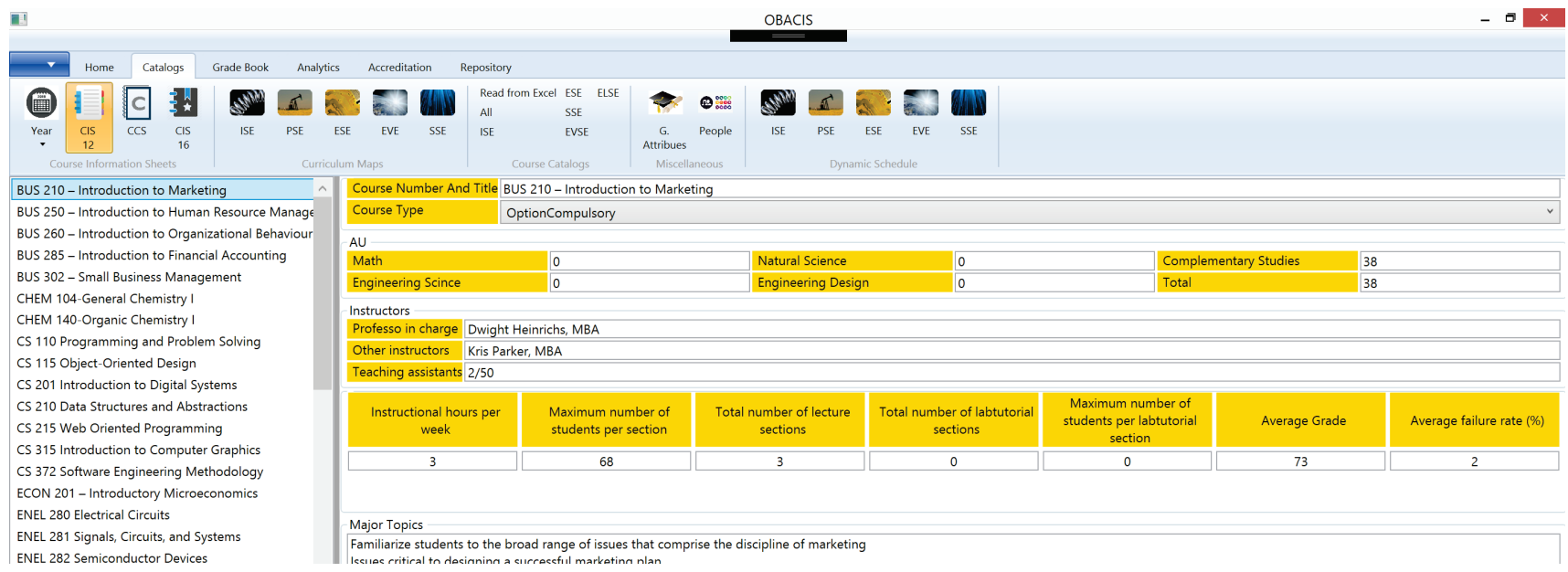

Figure 9: Legacy CIS Explorer

milestone to check the implications of the new systems and its impact on the development of the Canadian Engineering programs. Accreditation catalog is one of the artifacts that we would like to propose for the continuous improvement activities. Figure 6 shows a sample of CEAB's CIS of 2012 utilized by $\mathrm{U}$ of $\mathrm{R}$ during the last accreditation visit of 2012.

\subsection{Course Content Sheets (CCS) Catalog}

Course Content Sheets (CCS) are used at U of R to collect course related information such as AU entries: ES, ED, and $\mathrm{CS}$; assessment tools; and learning outcomes. Figure 9 shows the CCS catalog.

\section{AUTO-GENERATED COURSE INFORMATION SHEETS}

Now that we have all those catalogs at hand for all courses all the required data to fill up course information sheets could be updated on the spot. OBACIS can emit the autogenerated CISs as Excel files to be downloaded by the teaching faculty to be reviewed and updated wherever necessary. Depending on the data availability, the estimated time saving could range from $70 \%-90 \%$. Figure 10 shows the new auto generated CIS that duplicates the CEAB [10] design and specs of 2016. We propose extending the structure of CIS to meet continuous improving activities: sections related to course contents, assessment tools, additional teaching materials could be added and easily maintained to facilitate continues improvement activities.

\section{SUMMARY AND CONCLUSIONS}

In this paper, we introduced a novel accreditation database system that reduces the time needed for creating course information sheets mandated by CEAB by an order of magnitude and sets the grounds for a program- and faculty-level continuous improvement system. The system has been architected to compile many data fragments from several resources regardless their original formats. A parsing engine has been utilized to collect all the data 


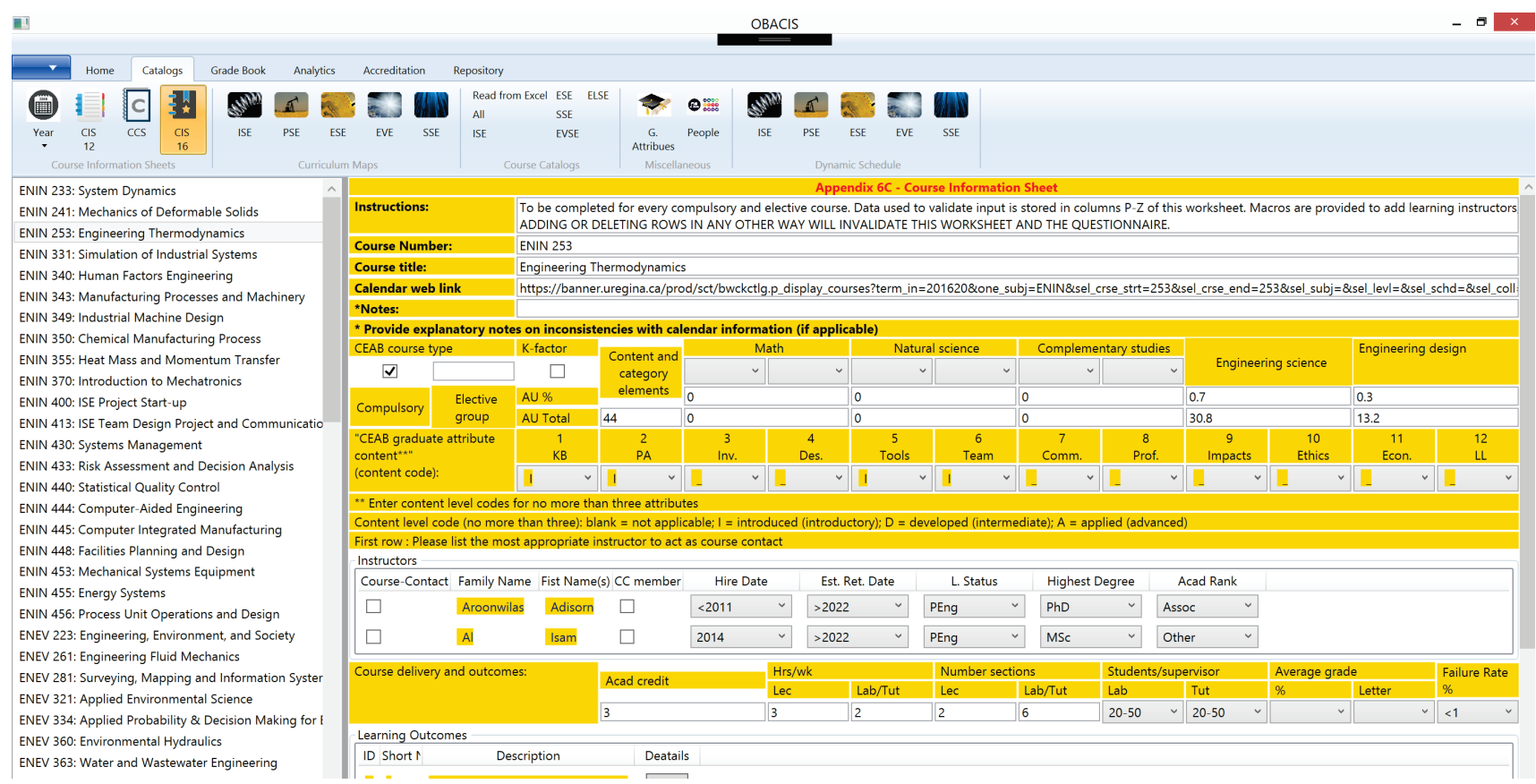

Figure 10: Course Content Sheets (According to CEAB 2016 Questionnaire)

needed and create a unified XML database that has been utilized to create several catalogs that should serve accreditation data collection, analyses, and reporting operations. The system has been implemented as a module within the bigger OBACIS system proposed in [1]. Program heads, associate deans, and deans of engineering are typical users of the Win-App and its catalogs databases. Generated reports can be distributed to curriculum and accreditation committee members to initiate or evaluate current and future action plans and relate them to continuous improvement projects or initiatives.

\section{ACKNOWLEDGEMENTS}

The author would to like to thank Dr. David deMontigny for the sharing Course Information Sheets of the last accreditation visit and Dr. Tontiwachwuthikul, Dr. Torabi, and Dr. Veawab for sharing their personal information. Special thanks go to those who gave positive feedback and encouraging words for the OBACIS project.

\section{DISCLAIMER}

OBACIS is still a work in progress and the data presented is just for testing and demonstration purposes. Some data have been either partially hidden or partially disguised for confidentiality reasons.

\section{REFERENCES}

1. Ismail, M., OBACIS: Outcome Based Analytics and Continuous Improvement System, in
Canadian Engineering Education Association (CEEA16)2016.

2. Kaupp, J. Using $R$ to Collect, Analyze and Visualize Graduate Attribute Data. in Canadian Engineering Education Association (CEEA16) 2016. Halifax, Nova Scotia

3. Kaupp, J. and B. Frank. EGAD National Snapshot Survey: Change, Progress and Improvement. in Canadian Engineering Education Association (CEEA16) 2016. Halifax, Nova Scotia

4. Brennan, R.W., et al. Evaluating an Integrated Course Design Tool for Engineering Graduate Attributes Assessment. in Canadian Engineering Education Association (CEEA16) 2016. Halifax, Nova Scotia

5. Ismail, M., OBACIS Accreditation and Grading Sheets (AGSs): The Xl-App, in Canadian Engineering Education Association (CEEA17)2017.

6. Essa, E., et al., ACAT: a web-based software tool to facilitate course assessment for ABET accreditation, in The 7th International Conference Information Technology2010: Las Vegas, USA.

7. Dew, S.K., M. Lavoie, and A. Snelgrove, An engineering accreditation management system, in Canadian Engineering Education Association 2nd Conference 2011 June: St. John's, Newfoundland, Canada. 
Proc. 2017 Canadian Engineering Education Association (CEEA17) Conf.

8. Ibrahim, W., et al., A Web-Based Course Assessment Tool with Direct Mapping to Student Outcomes. Educational Technology \& Society, , 2015. 18 (2): p. 46-59.

9. $\quad$ http://engineering.queensu.ca/egad. Engineering Graduate Attribute Development (EGAD) Project Last Accessed May, 2016

10. (CEAB), C.E.A.B., Questionnaire for Evaluation of an Engineering Program 2016.

CEEA17; Paper 171

University of Toronto; June $4-7,2017 \quad-8$ of $8-$ 